\title{
Multiple endocrine neoplasia type 1 in Poland: a two-centre experience
}

\author{
Przemysław Soczomski ${ }^{1}$, Beata Jurecka-Lubieniecka ${ }^{1}$, Natalia Rogozik ${ }^{2}$, Andrzej Tukiendorf ${ }^{3}$, \\ Barbara Jarząb ${ }^{1}$, Tomasz Bednarczuk²
}

${ }^{1}$ Department of Nuclear Medicine and Endocrine Oncology, Maria Sklodowska-Curie Institute — Oncology Centre Gliwice Branch, Gliwice, Poland

${ }^{2}$ Department of Internal Diseases and Endocrinology, Medical University of Warsaw, Warsaw, Poland

${ }^{3}$ Department of Public Health, Wroclaw Medical University, Wroclaw, Poland

\begin{abstract}
Introduction: Multiple endocrine neoplasia type 1 (MEN1) has been causing problems for clinicians since it was first described in 1954 by Wermer. Not only its rarity, but also its variable clinical manifestations and lack of genotype-phenotype correlation make it hard to establish evidence-based guidelines for the management of this syndrome. Nationwide registers and population-based research are the best means to improve knowledge about this rare disease. As yet, there is no example of such research in the Polish population of MEN1 patients. Material and methods: We performed a retrospective analysis of clinical and genetic data of patients diagnosed with MEN1 syndrome and followed-up in two polish referral centres in the years 1994-2018.

Results: We analysed 79 patients, of whom the majority were women. The mean age of the patient population was 43 years, mean age at MEN1 diagnosis was 37.95 years, and mean interval from initial symptoms to MEN1 diagnosis was 6.93 years. Primary hyperparathyroidism (PHP), gastroenteropancreatic neuroendocrine tumour (GEP-NET), and pituitary adenoma (PA) developed in $90 \%, 52 \%$, and $47 \%$ of patients, respectively. The dominance of insulinoma with low prevalence of gastrinoma is the most vivid difference, when compared to previously described populations. Moreover, we found 3.5-fold higher risk of developing a pituitary tumour in patients with a frameshift mutation with the STOP codon of the MEN1 gene.

Conclusions: The Polish population of patients with MEN1 is different than previously described European and Asian populations, primarily in prevalence of functional NETs. A frameshift mutation with the STOP codon of the MEN1 gene significantly increases the risk of PA. Further studies with a larger cohort of patients are needed to fully describe the Polish population and improve diagnosis and management of the syndrome. (Endokrynol Pol 2019; 70 (5): 385-391)
\end{abstract}

Key words: multiple endocrine neoplasia type 1; MEN1; Polish population; genotype-phenotype correlation

\section{Introduction}

Multiple Endocrine Neoplasia type 1 (MEN1) is a rare, genetically conditioned syndrome predisposing to primary hyperparathyroidism (PHP), neuroendocrine tumours of the gastric tract (GEP-NET), pituitary adenomas (PA), and other endocrine and non-endocrine tumours. This disorder is caused by germline mutation of a tumour suppressor gene that is located at 11q13 locus and encodes a protein called menin. The majority of cases are familial, with an autosomal-dominant inheritance pattern, but in approximately $10 \%$ it can also appear sporadically due to de novo mutations [1]. The estimated prevalence of MEN1 in post-mortem studies is $0.25 \%$ and in vivo is about $2-3$ per 100,000 individuals [1-3]. What seems to be most important for the patients is an increased risk of premature death and impaired quality of life, related to the syndrome [4-8].
Due to the sparsity of the syndrome, it is challenging to perform high-quality research and then establish evidence-based guidelines for therapy [6,9]. Therefore, therapeutic schemes of non-genetically conditioned endocrine tumours have been used in such cases, in spite of remarkable differences [10].

The need for nationwide cohort studies and national registers of rare diseases has been mentioned in many papers $[9,11,12]$, and now we have such examples in European and Asian populations [4, 13-16]. Despite these multi-centre studies, which analyse large groups of patients (from 258 to 734), there have also been papers presenting single-centre experiences $[17,18]$. In all of these studies, female dominance of up to $64 \%$ is noted, and the prevalence of typical tumours varies at $77-96 \%, 46-59 \%$, and 32-53\% for PHP, GEP-NET, and $\mathrm{PA}$, respectively. None of these research papers reports a significant correlation between the genotype and 
phenotype. However, the cohort studies are susceptible to different kinds of bias, including selection and information [6].

The aims of this study were clarification of the clinical and genetic features of Polish patients with MEN1 and an attempt to establish a genotype-phenotype correlation. To the best of our knowledge, it is the first research to perform such an evaluation in recent years.

\section{Material and methods}

We retrospectively analysed clinical and genetic data collected between the years 2004 and 2018 in patients affected by MEN1. All of the data are from two referral endocrinological centres in Poland: - Department of Nuclear Medicine and Endocrine Oncology, Maria Sklodowska-Curie Institute - Oncology Centre, Gliwice Branch; - Department of Internal Diseases and Endocrinology, Medical University of Warsaw.

We gathered information about the following: date of birth, gender, first MEN1 manifestation (type and age of onset), age at MEN1 diagnosis, family history, all MEN1-associated endocrine tumours, past and current treatment, and type of MEN1 gene mutation.

MEN1 diagnosis was established according to current guidelines [1]. Nevertheless, patients with clinical diagnosis but negative genetic test for a MEN1 gene mutation were not included in the data base. In 17 patients diagnosed before 2012 we used the previous guidelines [19].

Mutational analysis of the MEN1 gene was undertaken in all of the patients suspected of having MEN1 syndrome according to clinical symptoms. PCR-based Sanger sequencing of genomic DNA from a peripheral blood sample was performed. In all of the patients, exons 2-10 of the MEN1 gene and introns involved in the alternative splicing process were analysed. Next Generation Sequencing (NGS) and Multiplex ligation-dependent probe amplification (MLPA) were introduced in 2017 and used in mutational analysis in the patients previously considered negative for a MEN1 gene mutation in Sanger sequencing.

When a patient was positive for a MEN1 gene mutation, mutational analysis was performed in first-line family members as well.

The data are presented as mean with standard deviation (SD), median, and percentage. Logistic regression was used to assess the impact of the mutation type and the exon involved in the mutation on the occurrence of the studied clinical events. The strength of the association between the analysed variables and the clinical event was expressed as a classical odds ratio (OR). For all the statistical analysis performed, $\mathrm{p}<0.05$ was considered significant.

\section{Results}

By the end of December 2018, 95 patients met the diagnostic criteria of MEN1 syndrome and were included in the database. In 15 cases (16\%) only the information about sex, age, family history, and type of genetic mutation was provided, and one case was lost to follow-up. These cases were excluded from further analysis.

\section{Patients general characteristics}

Out of 79 registered patients $59.49 \%$ (47 patients) were women and $40.51 \%$ (32 patients) were men, with a mean age of 43.00 (SD 16.21) years and median age of 42 years. Faxmily history of MEN1 syndrome was present in $67.09 \%$ of patients, from whom 18 different families were noted.

The mean age at MEN1 diagnosis was 37.95 $(\mathrm{SD} \pm 15.87)$ years, and the median age was 36.5 years. The mean age at MEN 1 diagnosis in subgroups of index cases and family members was 38.63 (SD \pm 14.13 ) and 36.6 (SD \pm 18.59$)$ years, respectively. All of the general data about patients are presented in Table I.

In most of the cases, the initial symptoms were caused by PHP (renal stones, bone fractures, randomly diagnosed hypercalcaemia, or parathyroid tumour in imaging study). The prevalence of all of the observed initial symptoms is presented in Figure 1. The mean interval from the initial symptoms to MEN1 diagnosis was 6.93 (SD \pm 8.27 ) years. Delays between the diagnosis of a particular tumour and MEN1 are presented in Table II.

\section{Prevalence of tumours}

Primary hyperparathyroidism was the most prevalent MEN1-associated lesion. It occurred in 71 (89.87\%) cases and was the initial lesion in 37 cases. The mean age at PHP diagnosis was $35.99(\mathrm{SD} \pm 14.00)$ years with a mean delay of 2.49 (SD \pm 4.80 ) years to MEN1 diagnosis. Surgery was performed in $74.65 \%$ of patients. Out of these, $77.36 \%$ had a subtotal parathyroid excision;

Table I. General characteristics of population

\begin{tabular}{|c|c|c|c|}
\hline & All & Index cases & Family members \\
\hline \multirow{2}{*}{ Sex } & W: 47 (59.49\%) & W: 33 (67.35\%) & W: 14 (46.67\%) \\
\hline & M: 32 (40.51\%) & M: 16 (32.65\%) & M: 16 (53.33\%) \\
\hline Mean age [years] & $\begin{array}{c}43 \\
S D \pm 16.21\end{array}$ & $\begin{array}{c}44.61 \\
S D \pm 14.89\end{array}$ & $\begin{array}{c}36.6 \\
\mathrm{SD} \pm 18.59\end{array}$ \\
\hline Median age [years] & 42 & 42 & 42 \\
\hline $\begin{array}{l}\text { Mean age at MEN1 diagnosis } \\
\text { [years] }\end{array}$ & $\begin{array}{c}37.95 \\
S D \pm 15.87\end{array}$ & $\begin{array}{c}38.63 \\
S D \pm 14.13\end{array}$ & $\begin{array}{c}36.6 \\
S D \pm 18.59\end{array}$ \\
\hline
\end{tabular}

W - women; M — men; SD — standard deviation 


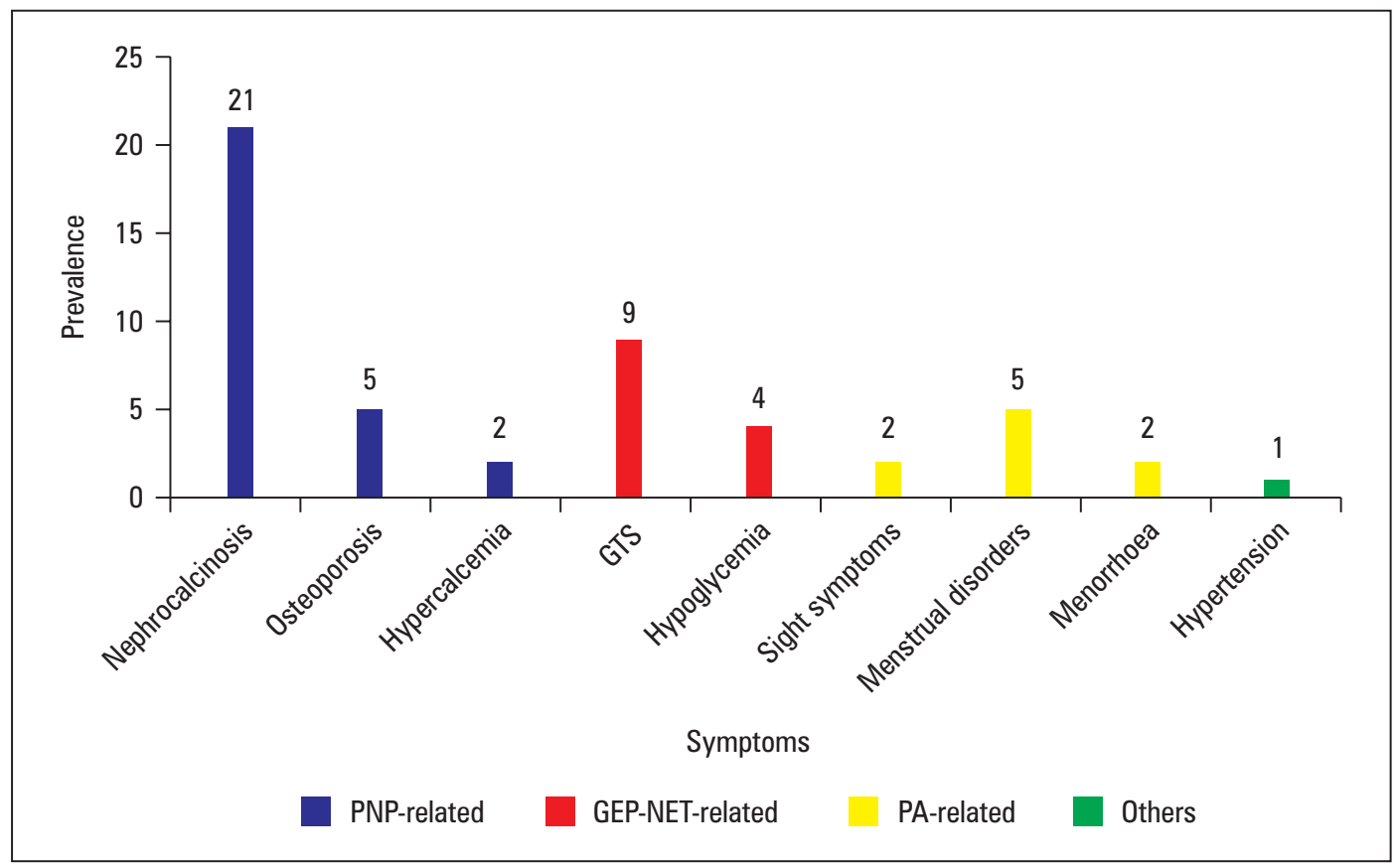

Figure 1. Prevalence of initial symptoms in the population. GTS - gastric tract symptoms (abdominal pain, peptic ulcers, diarrhoea); PNP — primary hyperparathyroidism; GEP-NET — gastroenteropancreatic neuroendocrine tumours; PA — pituitary adenoma

Table II. Delays between onset of the first symptoms and diagnosis of particular tumours to MEN1 diagnosis

\begin{tabular}{lccc}
\hline & All & Index cases & Family members \\
\hline \multirow{2}{*}{ First symptoms-MEN1 [years] } & 6.39 & 7.83 & 5.0 \\
& $\mathrm{SD} \pm 8.27$ & $\mathrm{SD} \pm 8.09$ & $\mathrm{SD} \pm 8.5$ \\
\hline \multirow{2}{*}{ PNP-MEN1 [years] } & 2.49 & 3.2 & 1.17 \\
\hline \multirow{2}{*}{ GEP-NET-MEN1 [years] } & $\mathrm{SD} \pm 4.8$ & $\mathrm{SD} \pm 5.59$ & $\mathrm{SD} \pm 2.35$ \\
\hline \multirow{2}{*}{ PA-MEN1 [years] } & 1.45 & 1.73 & 0.6 \\
& $\mathrm{SD} \pm 5.43$ & $\mathrm{SD} \pm 6.22$ & $\mathrm{SD} \pm 1.43$ \\
\hline
\end{tabular}

PNP — primary hyperparathyroidism; GEP-NET — gastroenteropancreatic neuroendocrine; MEN1 — multiple endocrine neoplasia type 1; PA — pituitary adenoma

$15.09 \%$ had a total parathyroidectomy and $43.40 \%$ had two or more procedures.

GEP-NET appeared in 41 cases $(51.90 \%)$ and was the initial lesion in 13 cases. The mean age at GEP-NET diagnosis was $41.2(\mathrm{SD} \pm 14.45)$ years with a mean delay of 1.45 (SD \pm 5.43 ) years to MEN1 diagnosis. In 40 cases it was a pancreatic neuroendocrine tumour (pNET), with concomitant neuroendocrine tumour of the duodenum in two patients. In one case there was no identified origin of the tumour. Hormonal analysis revealed $26.83 \%$ of functional tumours; the majority being insulinoma $(19.51 \%)$, followed by gastrinoma $(7.32 \%)$, and glucagonoma $(2.44 \%)$. There was no confirmed VIP-oma. In $56.10 \%$ of patients surgery was performed. Out of these, $30.43 \%$ had a tumour enucleation; $60.87 \%$ had a distal pancreatectomy, and only one patient had total pancreatectomy. A pharmacological approach, with somatostatin analogues, was noted in $39.02 \%$ of patients. Other neuroendocrine tumours were observed in five cases $(6.33 \%)$. Three of them were located in the lungs, one in the retroperitoneal space, and one in the stomach.

Pituitary adenoma occurred in $37(46.84 \%)$ patients and was the initial lesion in only seven cases. More than half of the lesions were classified as microadenoma. The mean age at PA diagnosis was $36.72(\mathrm{SD} \pm 15.35)$ years with a mean delay of $1.6(\mathrm{SD} \pm 5.85)$ years to MEN1 diagnosis. Abnormal hormonal secretion was observed in $62.16 \%$ of tumours with the dominance of prolactin (43.24\%) followed by GH (10.81\%), ACTH $(8.11 \%)$, and LH and FSH (both 2.7\%). Treatment consisted of surgery in $37.84 \%$ of patients and dopamine-agonist therapy in $45.95 \%$ of cases.

Five patients $(6.33 \%)$ did not present any typical MEN1 tumours. All of the data about the prevalence and characteristics of the lesions are presented in Table III. 
Table III. Characteristics of MEN1-associated tumours

\begin{tabular}{lccccc}
\hline & Prevalence & $\begin{array}{c}\text { Mean age } \\
\text { at diagnosis [years] }\end{array}$ & $\begin{array}{c}\text { Prevalence of } \\
\text { functional tumours }\end{array}$ & Surgery & Pharmacotherapy \\
\hline PHP & $71(89.87 \%)$ & $\begin{array}{c}35.99 \\
S D \pm 14.00\end{array}$ & - & $53(74.65 \%)$ & NA \\
\hline GEP-NET & $41(51.90 \%)$ & $\begin{array}{c}41.20 \\
S D \pm 14.45\end{array}$ & $26.83 \%$ & $23(56.10 \%)$ & $16(39.02 \%)$ \\
\hline PA & $37(46.84 \%)$ & $\begin{array}{c}36.72 \\
\text { SD } \pm 15.35\end{array}$ & $62.16 \%$ & $14(37.84 \%)$ & $17(45.95 \%)$ \\
\hline CA & $22(27.85 \%)$ & $\mathrm{NA}$ & $0 \%$ & $18.18 \%$ & $\mathrm{NA}$ \\
\hline Parcinoid & $5(6.33 \%)$ & $\mathrm{NA}$ & $\mathrm{NA}$ & $\mathrm{NA}$ & $\mathrm{NA}$ \\
\hline
\end{tabular}

PNP — primary hyperparathyroidism; GEP-NET — gastroenteropancreatic neuroendocrine tumours; PA — pituitary adenoma; AA — adrenal adenoma; SD — standard deviation; NA - not assessed

\section{Genetic data}

All of the patients had MEN1 gene mutation analysis performed, but we did not receive a specific description of gene mutation in two cases referred from other departments, so they were excluded from further statistical analysis. Prevalence of types of mutations and involved exons is presented in Figures 2 and 3, respectively. We found a statistically significant, 3.5 -fold higher risk of developing the pituitary tumour when frameshift mutation with the STOP codon appeared. The estimates from the univariate and multivariate regressions are displayed in Table IV.

\section{Discussion}

The aim of the study was to evaluate the Polish population of MEN1 patients and to seek any genotype-phenotype correlations. The Centre of Oncology in Gliwice and the Medical University of Warsaw are tertiary referral centres where genetic analysis of the MEN1 gene is performed and patients from all over the country are treated.
In recent years, there has been considerable interest in population-based studies analysing MEN1 patients, resulting in many papers describing European and Asian populations [4, 13-18]. Until now, mostly papers describing single cases of polish patients with MEN1 were published [20,21]. We found only one research paper describing a Polish population. Krassowski characterised a smaller number of patients from a single centre and diagnosed them on the basis of Gubbio Consensus. Patients were diagnosed at a younger age and the reported prevalence of typical lesions was higher, but the same tendency in insulinoma dominance was noticed [22].

Although genetic determination of disease should result in equal prevalence in both sexes, we observed female dominance, similarly to previously published population-based studies $[13,15,17]$. We found that the mean age at MEN1 diagnosis was only slightly higher for index cases than for family members. Our results, compared with other papers, suggest that we usually establish a MEN1 diagnosis earlier, and there is a smaller

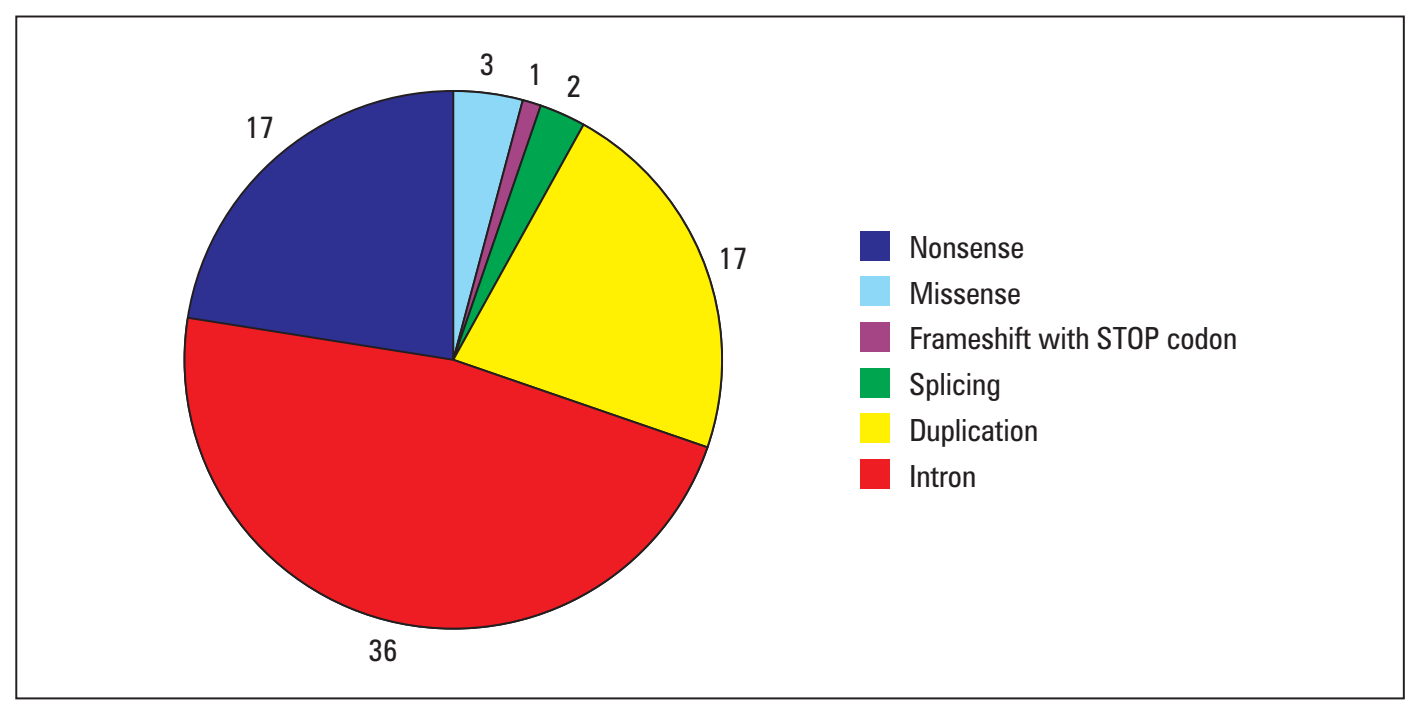

Figure 2. Prevalence of particular types of MEN1 gene mutations 


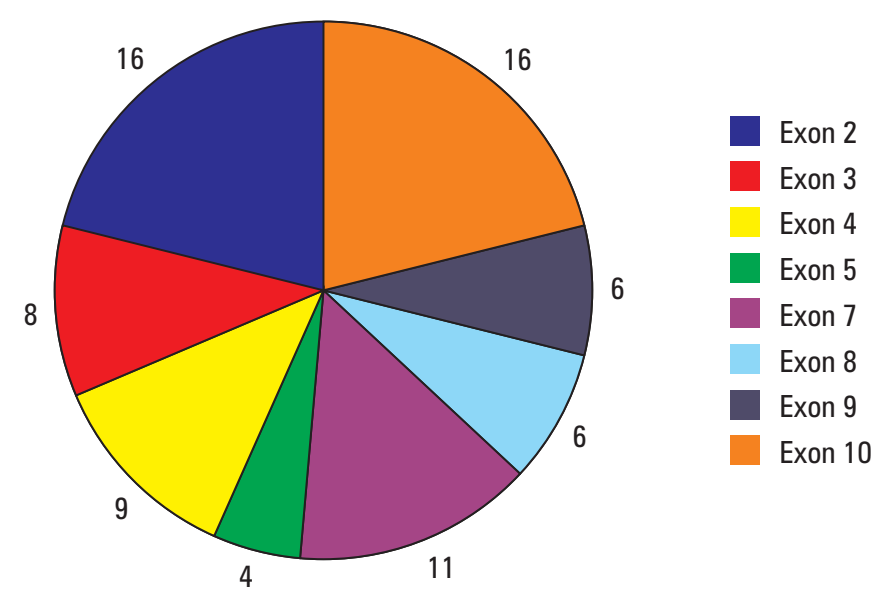

Figure 3. Prevalence MEN1 gene exons involved in mutations. Exon 6 was not involved in mutation in our database

Table IV. Odds ratios of impact of type of mutations and involved exons on the analysed clinical events

\begin{tabular}{lcccc}
\hline Clinical event & Risk factor & OR & 95\% Cl & p-value \\
\hline PNP & Nonsense & 0.69 & $(0.12,3.94)$ & 0.681 \\
\hline PNP & Missense & 0.61 & $(0.13,2.94)$ & 0.54 \\
\hline PNP & Frameshift with STOP codon & 1.81 & $(0.2,16.18)$ & 0.595 \\
\hline PNP & Splicing & NA & NA & NA \\
\hline PNP & Duplication & NA & NA & NA \\
\hline PNP & Exon & 0.92 & $(0.71,1.19)$ & 0.537 \\
\hline GEP-NET & Nonsense & 1.09 & $(0.37,3.2)$ & 0.879 \\
\hline GEP-NET & Missense & 0.82 & $(0.33,2.01)$ & 0.658 \\
\hline GEP-NET & Frameshift with STOP codon & 1.09 & $(0.37,3.2)$ & 0.879 \\
\hline GEP-NET & Splicing & 0.95 & $(0.06,15.72)$ & 0.97 \\
\hline GEP-NET & Duplication & NA & NA & NA \\
\hline GEP-NET & Exon & 0.98 & $(0.85,1.14)$ & 0.805 \\
\hline PA & Nonsense & 0.72 & $(0.24,2.16)$ & 0.563 \\
\hline PA & Missense & 0.58 & $(0.23,1.44)$ & 0.236 \\
\hline PA & Frameshift with STOP codon & 3.5 & $(1.09,11.23)$ & 0.035 \\
\hline PA & Splicing & NA & NA & NA \\
\hline PA & Duplication & NA & NA & NA \\
\hline PA & Exon & 0.93 & $(0.8,1.08)$ & 0.343 \\
\hline PNP & & PA & &
\end{tabular}

PNP — primary hyperparathyroidism; GEP-NET — gastroenteropancreatic neuroendocrine tumours; PA — pituitary adenoma; NA — not assessed tumours;

$\mathrm{PA}$ - pituitary adenoma

difference between the age at diagnosis in index cases and family members $[13,14,23,24]$. That is possible because of early implementation of genetic analysis for all the first-line family members on the basis of clinical presentation. Significantly lower age at MEN1 diagnosis was described by Pieterman [18], and this may be related to greater experience in management of MEN1 patients at this centre (patients collected since 1978).
Delays in the diagnosis of MEN1 are an important feature to evaluate, because it was claimed that earlier diagnosis improves the outcome [23-25]. Reducing the interval from symptoms to diagnosis appears to be crucial, especially in GEP-NETs, being the main cause of death in MEN1 patients [5,26]. It is difficult to compare our data with other papers concerning that problem because there are differences in methodology. 
Yamazaki et al. reported delays of MEN1 diagnosis from -2.9 to 5.3 years, depending on different signs, tumours and proband/family member status [24]. Giudici et al. observed 5.7 years of delay from GEP-NET to MEN1 diagnosis, which is significantly longer than observed in our database [27]. Leeuvaarde et al. described markedly longer delays in diagnosis of particular lesions, but the authors analysed only non-index cases, and the delays decreased in the course of time [23]. Our data reveal delays from -0.73 to 3.2 years depending on the tumour and index case/family member status. We observed the longest delays in PHP, which may be caused by non-specific or lack of symptoms and poor differentiation between sporadic PNP and PNP associated with genetic syndrome.

We reported similar prevalence of main MEN1-related tumours to that observed previously in other populations [4, 13-18]. Surprisingly, we found a slightly lower percentage of functional pNETs with a markedly lower incidence of gastrinoma and higher incidence of insulinoma [13, 14, 17, 28]. The rare use of endoscopic ultrasound (EUS) in one of our centres is one of the possible explanations of the minor underdiagnosis of pNET in our cohort, especially considering the fact that EUS has been described to be one of the most accurate tools to diagnose pNETs $[6,29]$. The prevalence of insulinoma and gastrinoma observed in other studies (11-22\% and $26-56 \%$, respectively) suggests that we underdiagnosed gastrinoma. We based the diagnosis of gastrinoma on clinical symptoms and biochemical tests, including fasting serum chromogranin A and gastrin levels. We did not imply (as recommended in guidelines) selective arterial secretagogue injection test and evaluation of basal acid output, which could lead to low prevalence of gastrinoma [1,30]. Moreover, it can be assumed that in Poland patients with gastrinoma are treated by other specialists such as surgeons and gastrologists, which could also have an impact on the percentage of observed gastrinomas in our database. On the other hand, it is the second study to observe higher prevalence of insulinoma in Polish patients with MEN1 syndrome, and it may be a feature of this population [22]. Importantly, we analysed only patients with MEN1 gene mutations, which could have an impact on reported percentages of typical tumours in comparison to other populations where also patients with clinical diagnosis and negative genetic mutation were analysed [4].

Many researchers have attempted to find a genotype-phenotype correlation in MEN1 syndrome [31-33]. Despite all these reports, clear correlation of clinical presentation and genotype has not been established in MEN 1 syndrome [34]. One of the most important findings of our research is a statistically significant, 3.5-fold higher risk of developing a pituitary adenoma when a frameshift mutation with a STOP codon is present. Considering our finding we should carefully seek pituitary tumours in patients with a frameshift mutation with a STOP codon, but further studies including larger groups of patients are needed to establish strong recommendations.

A limitation of our work is the cohort size, which is relatively small compared to other papers regarding this subject. Nevertheless, the sample of the Polish population with MEN1 syndrome analysed in our research is more than three-fold larger than previously analysed by Krassowski. Being tertiary referral centres, we are aware of the possibility of selection bias as we usually treat patients with advanced diseases from the whole Poland.

Nonetheless, considering the rarity of the disease, we believe that it is a meaningful contribution not only to describe the Polish population of MEN1 patients but also to general knowledge about the syndrome. Moreover, we assume that the publication of these findings will encourage other clinicians treating MEN1 in Poland to cooperate, which will result in analysis of a larger cohort in the future and decrease or even eliminate the selection bias.

\section{Conclusions}

The Polish population with MEN1 syndrome is different from previously described populations, especially considering lower prevalence of functional pNETs among which insulinoma was dominant. Patients with frameshift mutations with a STOP codon of the MEN1 gene are at 3.5-fold higher risk of developing a pituitary tumour, and for that reason they should be carefully followed up for this tumour. Further studies with a larger cohort of patients should be performed to establish more precise data about the Polish population with MEN1 syndrome.

\section{Conflicts of interest}

The authors do not disclose any conflicts of interest.

\section{Funding}

The research was not funded by any grants or other external sources.

\section{Authors contribution}

P.S. - conception, design, investigations, analysis of data, writing of the manuscript; B.J.L. - conception, design, analysis of data, review, supervision; N.R. - investigations, analysis of data; A.T. — statistical analysis; B.J. - review, supervision; T.B. - review, supervision. 


\section{References}

1. Thakker RV, Newey PJ, Walls GV, et al. Endocrine Society. Clinical practice guidelines for multiple endocrine neoplasia type 1 (MEN1). J Clin Endocrinol Metab. 2012; 97(9): 2990-3011, doi: 10.1210/jc.2012-1230, indexed in Pubmed: 22723327.

2. Marini F, Falchetti A, Del Monte F, et al. Multiple endocrine neoplasia type 1. Orphanet J Rare Dis. 2006; 1: 38, doi: 10.1186/1750-1172-1-38, indexed in Pubmed: 17014705.

3. Dreijerink KMa, Lips CJm. Diagnosis and Management of Multiple Endocrine Neoplasia Type 1 (MEN1). Hered Cancer Clin Pract. 2005; 3(1): 1-6, doi: 10.1186/1897-4287-3-1-1, indexed in Pubmed: 20223025.

4. de Laat JM, van der Luijt RB, Pieterman CRC, et al. MEN1 redefined, a clinical comparison of mutation-positive and mutation-negative patients. BMC Med. 2016; 14(1): 182, doi: 10.1186/s12916-016-0708-1, indexed in Pubmed: 27842554.

5. Ito T, Igarashi $\mathrm{H}$, Uehara $\mathrm{H}$, et al. Causes of death and prognostic factors in multiple endocrine neoplasia type 1: a prospective study: comparison of 106 MEN1/Zollinger-Ellison syndrome patients with 1613 literature MEN1 patients with or without pancreatic endocrine tumors. Medicine (Baltimore). 2013; 92(3): 135-181, doi: 10.1097/MD.0b013e3182954af1, indexed in Pubmed: 23645327.

6. Van Be, et al. 'Quality in, quality out', a stepwise approach to evidence-based medicine for rare diseases promoted by multiple endocrine neoplasia type 1. Endocr Connect. 2018 Nov; 7(11): R260-R274. Endocr Connect. 2018; 7(11): R260-R274., doi: 10.1530/EC-18-0359, indexed in Pubmed: 30352412.

7. van Leeuwaarde RS, Pieterman CRC, Bleiker EMA, et al. High Fear of Disease Occurrence Is Associated With Low Quality of Life in Patients With Multiple Endocrine Neoplasia Type 1: Results From the Dutch MEN1 Study Group. J Clin Endocrinol Metab. 2018; 103(6): 2354-2361, doi: 10.1210/jc.2018-00259, indexed in Pubmed: 29618015.

8. Berglund G, Lidén A, Hansson MG, et al. Quality of life in patients with multiple endocrine neoplasia type 1 (MEN 1). Fam Cancer. 2003; 2(1) 27-33, indexed in Pubmed: 14574164.

9. van Leeuwaarde RS, de Laat JM, Pieterman CRC, et al. The future: medical advances in MEN1 therapeutic approaches and management strategies. Endocr Relat Cancer. 2017; 24(10): T179-T193, doi: 10.1530/ERC-17-0225, indexed in Pubmed: 28768698.

10. Yates CJ, Newey PJ, Thakker RV. Challenges and controversies in management of pancreatic neuroendocrine tumours in patients with MEN1. Lancet Diabetes Endocrinol. 2015; 3(11): 895-905, doi: 10.1016/S2213-8587(15)00043-1, indexed in Pubmed: 26165399.

11. Leeuwaarde RS, Herder WW, Valk GD. The need for national registries for rare endocrine tumor syndromes. Endocrine. 2017; 58(2): 205-206, doi: 10.1007/s12020-017-1296-3, indexed in Pubmed: 28417312.

12. Aymé S, Rodwell C. The European Union Committee of Experts on Rare Diseases: three productive years at the service of the rare disease community. Orphanet J Rare Dis. 2014; 9: 30, doi: 10.1186/1750-1172-9-30, indexed in Pubmed: 24580800.

13. Sakurai A, Suzuki S, Kosugi S, et al. MEN Consortium of Japan. Multiple endocrine neoplasia type 1 in Japan: establishment and analysis of a multicentre database. Clin Endocrinol (Oxf). 2012; 76(4): 533-539 doi: 10.1111/j.1365-2265.2011.04227.x, indexed in Pubmed: 21950691.

14. Giusti F, Cianferotti L, Boaretto F, et al. Multiple endocrine neoplasia syndrome type 1 : institution, management, and data analysis of a nationwide multicenter patient database. Endocrine. 2017; 58(2): 349-359, doi: 10.1007/s12020-017-1234-4, indexed in Pubmed: 28132167.

15. Goudet P, Bonithon-Kopp C, Murat A, et al. Gender-related differences in MEN1 lesion occurrence and diagnosis: a cohort study of 734 cases from the Groupe d'etude des Tumeurs Endocrines. Eur J Endocrinol. 2011; 165(1): 97-105, doi: 10.1530/EJE-10-0950, indexed in Pubmed: 21551167.

16. Machens A, Schaaf L, Karges W, et al. Age-related penetrance of endocrine tumours in multiple endocrine neoplasia type 1 (MEN1) a multicentre study of 258 gene carriers. Clin Endocrinol (Oxf) 2007; 67(4): 613-622, doi: 10.1111/j.1365-2265.2007.02934.x, indexed in Pubmed: 17590169.

17. Marini F, Giusti F, Brandi ML. Multiple endocrine neoplasia type 1: extensive analysis of a large database of Florentine patients. Orphanet
J Rare Dis. 2018; 13(1): 205, doi: 10.1186/s13023-018-0938-8, indexed in Pubmed: 30428914.

18. Pieterman CRC, Schreinemakers JMJ, Koppeschaar HPF, et al. Multiple endocrine neoplasia type 1 (MEN1): its manifestations and effect of genetic screening on clinical outcome. Clin Endocrinol (Oxf). 2009; 70(4): 575-581, doi: 10.1111/j.1365-2265.2008.03324.x, indexed in Pubmed: 18616711.

19. Brandi ML, Gagel RF, Angeli A, et al. Guidelines for diagnosis and therapy of MEN type 1 and type 2. J Clin Endocrinol Metab. 2001; 86(12): 5658-5671, doi: 10.1210/jcem.86.12.8070, indexed in Pubmed: 11739416.

20. Buła G, Truchanowski W, Koziołek H, et al. A follow-up study of patients with MEN syndromes - five case reports. Endokrynol Pol. 2018; 69(2): 163-167, doi: 10.5603/EP.2018.0020, indexed in Pubmed: 29952424.

21. Debski MG, Makowska A, Bar-Andziak E. Insulinoma in a patient with MEN 1 syndrome - 9-year follow-up: case report. Endokrynol Pol. 2010; 61(2): 212-216, indexed in Pubmed: 20464709.

22. Krassowski J. Trudności w rozpoznawaniu i leczeniu MEN 1. Pol J Endocrinol. 2005; 3(56)

23. van Leeuwaarde RS, van Nesselrooij BPM, Hermus AdR, et al. Impact of Delay in Diagnosis in Outcomes in MEN1: Results From the Dutch MEN1 Study Group. J Clin Endocrinol Metab. 2016; 101(3): 1159-1165, doi: 10.1210/jc.2015-3766, indexed in Pubmed: 26751192.

24. Yamazaki M, Suzuki Si, Kosugi S, et al. MEN Consortium of Japan. Delay in the diagnosis of multiple endocrine neoplasia type 1: typical symptoms are frequently overlooked. Endocr J. 2012; 59(9): 797-807, indexed in Pubmed: 22673601.

25. de Laat JM, van Leeuwaarde RS, Valk GD. The Importance of an Early and Accurate MEN1 Diagnosis. Front Endocrinol (Lausanne). 2018, 9: 533, doi: 10.3389/fendo.2018.00533, indexed in Pubmed: 30254610.

26. Goudet P, Murat A, Binquet C et al. Risk factors and causes of death in MEN1 disease. A GTE (Groupe d'Etude des Tumeurs Endocrines) cohort study among 758 patients. World J Surg. 2010; 34(2): 249-255, doi: 10.1007/s00268-009-0290-1, indexed in Pubmed: 19949948.

27. Giudici F, Cavalli T, Giusti F, et al. Natural History of MEN1 GEP-NET: Single-Center Experience After a Long Follow-Up. World J Surg. 2017; 41(9): 2312-2323, doi: 10.1007/s00268-017-4019-2, indexed in Pubmed: 28429092

28. Donegan D, Singh Ospina N, Rodriguez-Gutierrez R, et al. Long-term outcomes in patients with multiple endocrine neoplasia type 1 and pancreaticoduodenal neuroendocrine tumours. Clin Endocrinol (Oxf). 2017; 86(2): 199-206, doi: 10.1111/cen.13264, indexed in Pubmed: 27770475 .

29. Ito T, Jensen RT. Imaging in multiple endocrine neoplasia type 1: recent studies show enhanced sensitivities but increased controversies. In J Endocr Oncol. 2016; 3(1): 53-66, doi: 10.2217/ije.15.29, indexed in Pubmed: 26834963.

30. Lipiński M, Rydzewska G, Foltyn W, et al. Gastroduodenal neuroendocrine neoplasms, including gastrinoma - management guidelines (recommended by the Polish Network of Neuroendocrine Tumours). Endokrynol Pol. 2017; 68(2): 138-153, doi: 10.5603/EP.2017.0016, indexed in Pubmed: 28540972.

31. Thevenon J, Bourredjem A, Faivre L, et al. Higher risk of death among MEN1 patients with mutations in the JunD interacting domain a Groupe d'etude des Tumeurs Endocrines (GTE) cohort study. Hum Mol Genet. 2013; 22(10): 1940-1948, doi: 10.1093/hmg/ddt039, indexed in Pubmed: 23376981

32. Bartsch DK, Slater EP, Albers M, et al. Higher risk of aggressive pancreatic neuroendocrine tumors in MEN1 patients with MEN1 mutations affecting the CHES1 interacting MENIN domain. J Clin Endocrinol Metab. 2014; 99(11): E2387-E2391, doi: 10.1210/jc.2013-4432, indexed in Pubmed: 25210877.

33. Christakis I, Qiu W, Hyde SM, et al. Genotype-phenotype pancreatic neuroendocrine tumor relationship in multiple endocrine neoplasia type 1 patients: A 23-year experience at a single institution. Surgery. 2018; 163(1): 212-217, doi: 10.1016/j.surg.2017.04.044, indexed in Pubmed: 29122330

34. Falchetti A. Genetics of multiple endocrine neoplasia type 1 syndrome: what's new and what's old. F1000Res. 2017; 6, doi: 10.12688/f1000research.7230.1, indexed in Pubmed: 28184288. 